\title{
La construcción de una ética articulada para una política Peri hermeneias
}

\author{
Prof. Ruth ROMERO HUAMANÍ
}

El objetivo del texto es hacer un análisis crítico de la construcción de una ética articulada desde el estudio político y cultural, con la finalidad de comprender dos condiciones íntimamente ligadas en el modus operandi cotidiano:

a. Contigencia de la finitud. Esta condición corresponde a la historicidad misma de la vivencia humana, es decir la forma en que se interpreta de manera dealógica la tradición constituida, esto es la cercanía de la carga sustancial del presente como el primer determinante de la propia vida en cuanto a la comprensión racional.

b. Re-edificación y la falsa hipostasía. Para evitar esta condición en las relaciones de poder dentro de las instituciones se debe asegurar un elemento que es el distanciamiento crítico en la interpretación. Esto porque la propia tradición, incluso los prejuicios subjetivos son parte del bagaje cultural de cada individuo.

Cuando la racionalidad e irracionalidad subjetiva y el apoderamiento del poder se encuentra en conflicto dentro de las intituciones, ya sea de manera subjetiva o intersubjetiva, parece no haber escapatoria de ese encuentro falso de los individuos sometidos a una norma utilitarista y pragmática. La presencia de las dos condiciones son tan dominantes porque conducen al yo a un mundo sin alternativas, por lo menos eso es lo que pasa cuando le echamos una mirada a esa realidad en los tiempos de crisis en la práctica moralidad.

Ahora bien, la hermenéutica, pues, nos lleva al entendimiento de ese mundo irracional de los humanos, brindando herramientas ontológicas para la construcción de una ética articulada. Esto no es sino, la naturaleza de la acción y la razón práctica que configura la intencional-significativa de la ética, y esta es la articulación de las fuentes morales en la práxis orientada fronéticamente para la Peri hermeneias política. Tesis que hemos calificado de la experiencia en el sentido fuerte de la palabra, es decir, desde la transformación óntica. 
La articulación en el seno de esta doble condicionalidad siempre es labor de la hermenéutica de evaluación e interpretación del papel de distintos bienes e hiperbienes, que tienen en nuestros proyectos de vida en el contexto de la filosofía ética y política, porque nos permite evitar las contigencias y las falsas hipostasías en los conceptos de acción de subjetividades e intersubjetivades conduciéndonos a una mejor fuente que la objetividad de acción de poder en las instituciones y la praxis de una moralidad racional y crítica.

Una ética articulada consiste en la capacidad de sostener ciertas preferencias y los criterios que están en el uso para discernir entre ellas, de manera argumentada y razonada, esto es de modo crítico y es por eso entendemos la fuerza que tienen los argumentos en la transformación de nuestros hábitos culturales, de nuestras relaciones con los demás, tanto en la vida privada como en lo público, en suma es el trasnfondo completo que nos constituye como agentes autointerpretantes. Por ello, la pertenencia de nuestra articulación no es tendencial u opcional si hemos cobrado conciencia de la importancia que tiene para la configuración de la identidad propia y ajena.

La ética articulada, de este género en cuyas discriminaciones evaluativas y argumentaciones críticas nos vamos constituyendo como personas, conduce dos vías de reflexión que muestran el despliegue de esta ética, que evita la masificación de las condiciones:

a. La argumentación a favor de una racionalidad práctica coherente con la estructura de la acción libre, que se distinga tanto de la razón de cálculo cientísta, que se arroja el utilitarismo, y otras opciones de la ética instrumental contemporánea, como de la razón meramente procedimental, vacía del contenido.

b. La forma de cómo mostrar esta racionalidad práctica fundamenta de que la idea en las articulaciones de nuestra acción se juega su libertad y su capacidad crítica de su autotransformación.

Para la primera ruta, los hitos del recorrido serán: uno, la propia reflexión de Taylor sobre la posibilidad de una racionalidad alternativa a su mera caracterización en "términos formales"; dos, como una desviación necesaria, pasando por la razón prudencial (y brevemente por el "cuidado" del ser ahí), la revisión de la postura de la reinterpretación de la idea de la frónesis de, antecedentes directos de una propuesta de una "ética articulada", problema a recurrir en la segunda ruta en el siguiente apartado y punto de llegada del recorrido.

De la alternativa de una racionalidad que opere no simplemente en términos formales depende en gran medida el proyecto de una ética articulada, esto es de una ética como hermenéutica de la situación concreta. Para desplegar 
tal, y siguiendo de una buena lógica de argumentación. Cabe plantear que en primer lugar se debe considerar lo que podemos entender por la racionalidad en términos formales, para después en una crítica negativa, demarcar sus límites y optar por otro tipo de racionalidad cuando de asuntos morales se trata.

La cuestión central es si hablando de racionalidad en general uno de sus rasgos centrales será la "inconsistencia" como suele opinarse dentro de algunas de las corrientes de pensamiento más en boga actualmente, o si ese riesgo será propio sólo de su formalización extrema, liberando así el tema hacia una idea de la racionalidad más amplia y rica ${ }^{1}$.

Tradicionalmente se dice de que una persona es inconciente cuando su pensamiento esta atrapado en afirmar al mismo tiempo "p y no p", esto es cuando lógicamente puede decirse que esta persona sería capaz de reconocer y formular las máximas y objetivos de su acción que estarían en contradicción como arguye Taylor, pero esta inconsistencia se ha igualado instantáneamente con nuestra idea de irracionalidad, y de aquí calificar de racionales, por tanto más legítimos y superiores, nuestras prácticas culturales en un obtuso etnocentrismo, y a descalificar otras prácticas y tacharlas de inferiores y no válidas, sólo hay un paso. Es justo aquí donde se comete una violencia innecesaria, pues se estrecha el sentido de la palabra racional para ajustarla a un uso local el que corresponde a la tradición intelectualista occidental en la que, al menos desde la Grecia clásica, la comprensión debe ser teorética, contemplativa, desarraigada de toda persona subjetiva (de la vida ordinaria) de deseos u objetivos y dirigida a conocer las cosas "como ellas son".

Existen dos razones de la ecuación "razón=consistencia", uno, que frente a las prácticas de poder diversas, lo diverso no puede calificarse sencillamente de "racionalidad de menor grado" o de franca irracionalidad por no responder a nuestros cánones lógicos de coherencia interna, y, dos que la acción moral concreta pide otro tipo de racionalidad que no sea teorética o contemplativa.

Hablando de la primera de estas razones se alude a los ejemplos que acostumbra a defender por ejemplo: frente a las prácticas extrañas como rituales institucionales, sistemas de derechos que justifican la discriminación o perpetraciones como la exclusión de la minorías, o, la clitoredermía, tendemos a calificarla de irracionalidad criminal, en el caso de rituales meramente simbólicos. Pero dar esta calificación es resolver la cuestión de la diversidad del poder cultural en forma demasiado simplista y apresurada, ya que habla desde la perspectiva, sin tomar en cuenta que la naturaleza misma de acción humana, exige comprenderla desde sus propios términos agentes.

1 Taylor, C., "Rationality", en Philosophy and the Human Sciences. Philosophical Pepers II, p.134. 
Lo que ha conducido a formalizar en extremo nuestra idea de racionalidad, y por tanto a ignorar este significado vital que dan los agentes a sus acciones, ha sido en gran medida la tendencia intelectualista del pensamiento, expresada sobre todo en las prácticas científicas y sus aplicaciones tecnológicas, que en la medida en que ignora o devalúa las dimensiones simbólicas y expresivas de la acción, tiende a describirlas desde una perspectiva objetivista, sin tomar en cuenta su integración radical con el mundo al que pertenece.

Sin embargo, una cosa es entender intelectualmente al mundo y otra muy distinta es estar en armonía o integrado a él, y sólo desde la última opción se puede hablar de una verdadera comprensión de los alcances de la razón en su medio de significación real.

Perspectiva en que el conocimiento y ser de una determinada forma en el mundo están unidos indisociablemente, el argumento etnocéntrico de la razón que violenta las prácticas culturales de poder extrañas se viene abajo, y aparece como una exigencia y considerarlas no como algo que puede ser juzgado bajo los mismos cánones de nuestro funcionamiento lógico de la razón, sino como algo abiertamente inconmensurable, y que para ello se requiere hacer juicios con una racionalidad culturalmente-entrecruzada.

Esta racionalidad es de la misma naturaleza que la racionalidad pre-científica, que se describe como una habilidad para vérselas con el mundo ( el ser ahí), cuyo significado es imposible hacer juicios de superioridad entre culturas, pues cada centro significativo conduce a una perspectiva del mundo que es inconmensurable con otra. Porque se puede hacer juicios de mayor o menor promiscuidad transculturalmente, acudiendo al principio de la mejor explicación (o principio BA), y a partir de ello se podría hablar de cierta superioridad en aspecto cultural cuando se confronta con otro (por ejemplo, hablando de la superioridad de la tecnología moderna respecto a la tecnología antigua o de la capacidad de conocimiento del mundo físico de la ciencia actual comparado con las explicaciones del mundo antiguo), pero esto no quiere decir que tengamos que dejar hablar de una pluralidad de estándares inconmensurables que aseguran que cierto avance en un aspecto cultural no implica una superioridad global de una cultura sobre otra, ni que una sea racional y la otra iracional.

Esto significa, seguir confundiendo racionalidad con consistencia interna culturalmente autocentrada, cuando el concepto de racionalidad es más amplio y flexible. El término racionalidad entendida en términos más puramente formales es una racionalidad que se enfrenta prácticamente tanto a su mundo como al mundo lejano o extraño culturalmente hablando, lo que quiere decir que se enfrenta a ellos desde el reto de interpretar sus transfondos significativos y actuar conforme a esta interpretación. Articular racionalmente el sentido de 
este transfondo, ya lo estamos viendo, supone una empresa moral de evaluación y discernimiento, que se define precisamente como un ser capaz de vérselas con el mundo concreto de manera apropiada. ¿Qué significan aquí las palabras de manera apropiada? ¿Cómo es que los agentes viven acorde a sus descripciones de sus significaciones vitales, y, cuando son enfrentados a otros mundos culturales, como es que han de conducirse?

Responderemos a estas preguntas insistiendo en el vínculo natural entre la ética phronetica y la defensa de la razón práctica. La idea de phronética sobre la dimensión práctica de la "recta razón" en apego a la prudencia (Aristóteles, libro VI de la EN) lleva a cabo un ejercicio de categorización de las diversas formas en que el hombre se puede enfrentar a su mundo y adquirir su verdad, ya de manera teórica, productiva o práctica, ejercicio que termina en una apología de la razón prudencial (o recta razón como virtud dianoética que se equilibra entre el exceso y el defecto), considerada como el hábito a la vida buena.

De los cinco formas de acercarse a la verdad -arte, o, poíesis, ciencia o episteme, prudencia o phrónesis, sabiduría o sofia, e intuición o nous- sólo la prudencia tiene el propósito de hacernos mejores. El pensamiento productivo (tejné) coincide con el acto moral en que busca los medios para un determinado fin, pero si bien es el primero se habla de un hacer cuyo fin es objeto producido como algo distinguible de esa operación, en el acto moral más bien se habla de un obrar en donde no hay distancia entre el acto y el fin, pues el acto mismo es su propio fin, esto es el agente actuando es el que se logra o no se logra en la ejercitación del acto.

De modo que, el hombre prudente comprometido en la empresa de su propia temporalidad, decara a la reinterpretación de su pasado para gestarse asimismo en el futuro, esto es, como proyecto de sí mismo, y por lo tanto como alguien que todavía no es todo lo que tiene que ser; por ello, no recurre a parámetros teóricos para orientarse a una introspección de la autoconciencia autoreflexiva, sino a su determinación práctica en el medio de sus disposiciones efectivas y sus relaciones con el mundo de las cosas y de los hombres, y que mediante en cuidado, como capacidad analógica de la prudencia aristotélica, se puede enfrentar. La phónesis remite en Heidegger, insiste Escudero, a la acción en la que el ser ahí se ve comprometido como un incesante proceso de realización, de elecciones que nadie puede tomar por él y que se observa en el proceso de singularización que sufre el ser ahí ante la angustia, de jugarse su ser en la propiedad y la impropiedad como un asunto eminentemente práctico.

La hermenéutica como problema práctico, enhebrado en la reactualización del tema de la aplicación por Gadamer, sigue a Aristóteles y a Heidegger, se puede observar desde sus implicaciones éticas, estas implicaciones reconsideradas por Taylor como razón práctica. 
La reactualización de la ética phronética tiene una relevancia hermenéutica, y esto por su alejamiento de la metafísica y la idea del bien como una generalidad vacía y la consiguiente apreciación de lo que es el bien para el ser humano concreto, esto es por su oposición del ethos, en donde se refleja la mutabilidad y contingencia de la situación humana, a la phisys en donde se reflejan las leyes eternas de las cosas inmutables. La línea que va de estas críticas aristotélicas a la consideración hermenéutica de Gadamer, y de ésta al problema hermenéuticoético que hay en Taylor cuando habla de topografía de la moral, en la que el agente humano ha de orientarse para obtener su identidad, se ve diáfanamente en las estimaciones del propio Gadamer.

El saber práctico de la moral de que aquí se habla, que implica un discernimiento hermenéutico de la circunstancia vivida, no puede ser como había dicho Aristóteles, de la exactitud metodológica máxima del matemático, o en la polémica Gadamer y Taylor vs. Habermas.

El saber del experto del racionalista en cualquiera de sus versiones, ni el del operario técnico, o bien de aquél que ejerce una mera razón instrumental, sino el saber de quien haciendo visible, el perfil de las cosas, y mediante esbozos, ejercita el hábito de una actitud en si mismo que tiene como resultado un "saber para si", un saber moral que sólo cuando se ejercita despliega sus verdadero potencial, esto es, no es la clase del saber que primero se tiene y luego se aplique, ya que no existe una determinación, a priori, para la orientación de vida correcta como tal, sino se trata de una comprensión llevada a cabo en forma efectual.

En la ética articulada el trasfondo que compone la significativa de nuestro mundo y desde el cual interpretamos y evaluamos nuestras opciones morales de vida, tiene la misma función fáctica que en Gadamer y Heidegger, y conduce con la misma necesidad, aunque en un marco de problemas nuevos, a la cuestión de la razón práctica y de la phrónesis como hábito de discernimiento.

La posibilidad de una ética articulada que no se pierde en una mera capacidad procedimental de argumentación, sino que en sus articulaciones media con la materialidad del mundo, significación en que surge, y justo por ello se define como capacidad práctica de ponderación, interrelación y evaluación de los medios, de la finalidad y de las condiciones de la acción en cada caso concreto. En este, insistimos, el único sentido en que las disertaciones de Taylor sobre este asunto pueden considerarse una defensa de un realismo moral.

Así es, como se ve, la articulación ética de la que venimos hablando, como señala Taylor, ni se reduce a la utilización de un criterio único aplicable preceptivamente (como la aplicación de una receta de pasos o de un dominio 
técnico, y en esto coincide con Aristóteles plenamente), ni es exclusiva de una teorización filosófica o científica que sólo los expertos podrían manejar.

Articular quiere decir, en un sentido muy amplio, encarnar un sentido en multitud de medios (...). Lo imprescindible de una articulación es que exprese el "todo de una vida" y como es que los distintos bienes se relacionan en ella de manera coimplicativa, cómo es que se integran sus pasajes Kairóticos irreversibles con los distintos ritmos y cambios de su temporalidad no uniformable, y cómo es que pudieran encadenarse según un modelo de vida que se quiere guiar, según una unidad básica de actos en el medio de diversidad (y oposición en ocasiones) de bienes. Pretender escapar de esta articulación no puede ser más que soberbia, una pretensión de control sobre la contingencia del mundo, un salto más allá de la vulnerable condición humana.

Trasfondo, explica, a las propiedades relevantes, o significativas de un contexto, en tanto que esquema se refiere a esa propiedades ya interiorizadas por el sujeto, hechas explícitas al menos en parte, y que constituyen entonces su marco de referencia significativo. Entonces, la articulación sería el paso de una a otra condición.

Este "dar cuenta de" en un medio de nuestro propio trasfondo, esta articulación inherente al campo de significación al que pertenecemos los agentes, pretende ser desarrollado por el escepticismo moral de su deformación de la razón práctica, el ecepsticismo en este caso es que una creencia muy extendida en nuestros días, propiciada en algún medida por la enorme diversidad cultural y moral, que afirma que sobre asuntos morales no se puede argumentar racionalmente, que la razón no puede arbitrar diferencias morales en apariencias inconciliables.

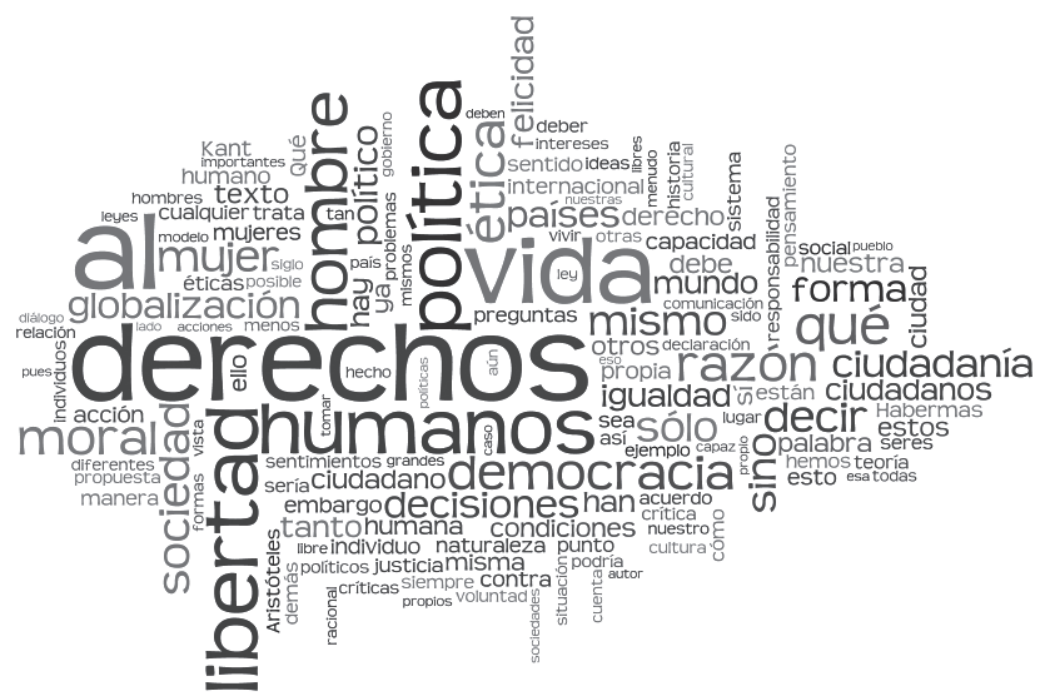

PALABRAS ÉTICAS 
Por tanto, la articulación de un hiperbien o de un bien, estos siempre son susceptibles, de ser criticados o desafiados, desde la perspectiva de nuestro crecimiento moral, y ante estos desafíos tendrán que ser defendidos argumentativamente refiriéndose siempre a la génesis histórica, a sus relevancia según el contexto dado. Es decir, la articulación de los bienes es parte fundamental del reconocimiento de la fuerza que tienen esos bienes en toda circunstancia humana, y de su carácter inesquivable de interpelación.

La articulación hermenéutica abre horizontes de acción según bienes advertidos y buscados, constituye tanto la significatividad de nuestro mundo como la propia identidad. En las narratividades de carácter histórico que estructuran esa articulación se juega la topografía moral que da sentido a nuestras acciones. En consecuencia, la coimplicación constitutiva entre el aspecto hermenéutico y el aspecto ético de la acción es unitaria como experiencia aunque discernible en cuanto a las perspectivas que se tengan de ella, se puede explicar con una enorme ganancia de claridad si nos remitimos a los términos taylorianos de capacidad de articulación de los bienes.

Antes esta enfaces, la utilidad práctica de este género no se agota en esta labor negativa de la crítica y restricción de los abusos de una razón instrumental o formalizada procedimental, ya sea en sus formas cientistas ya como la colección de recursos amañados de coersión y autoengaño que componen lo que se puede llamar una falsa conciencia. Esta también tiene utilidad positiva en posibilitar vías de nuevas valoraciones, modos de seguir de estilos de vida que se consideran legítimos y justos, por ejemplo la perfección y realización de los derechos humanos, con mayor respeto por los bienes culturales estimados en cada entorno, un trato menos violento y manipulador entre culturas, y cosas por estilo. Esto provoca una alternativa de comprensión y de actuación en el convulso mundo contemporáneo diferente a las meramente instrumentales, de un lado, y las que se evaden en forma de nihilismo pasivo, de otro lado.

De esta manera, pensamos que frente a los conflictos que se generan en los distintos programas de rescate de los valores de comunidades marginadas o violentadas por las razones más disímiles que se quiera, el modelo de una razón práctica, que dé cuenta genealógicamente de sus transformaciones en el tiempo y críticamente proponga una transición a una comprensión menos susceptible de errores de interpretación etnocentricos, es altamente valioso. Lo mismo sucede si se piensa en los problemas de generación e interpretación de un derecho occidental respecto a personas que por su bagaje cultural no siempre entienden el sentido de lo demandado o de las restricciones que impone: sólo una razón que decide la vía por la cual transita desde el terreno mismo de los hechos podría dar cuenta de casos de esta naturaleza. Y sólo empleando a fondo en resolver lo que ha llamado Taylor una "laguna fronética" en estos casos es que se pueden 
ver vías de solución que no requieren de la violencia en sus interpretaciones. Llevando estas interpretaciones a una construcción bien definida en la política sobre la peri hermeneis que es la construcción de una acción política cultural moralmente racional.

\section{BIBLIOGRAFÍA}

Cassirer, E. El mito del estado, FCE, México, 1985.

Camps, Victoria (2001), Introducción a la filosofia política, Ed. Crítica, Barcelona.

Carrasco, Alejandra (2001), Ética y liberalismo, RIL editores, Santiago.

Cristi, Renato (1998), "La crítica comunitaria a la moral liberal". Estudios Públicos $N^{\circ}$ 69, verano, Santiago.

Gadamer, G. Verdad y Mètodo. Fundamentos de una hermenéutica filosófica, Salamanca, Sígueme, 1977. Tr.: Ana Agud Aparicio y Rafael de Agapito.

Guariglia, Osvaldo (1996), Moralidad, ética universalista y sujeto moral, Ed. Fondo de Cultura Económica, Buenos Aires.

Gutmann, Amy (1993), "Introducción a Charles Taylor", en El multiculturalismo y "la política del reconocimiento", Ed. Fondo de Cultura Económica, México.

Taylor, C., "Rationality", en Philosophy and the Human Sciences. Philosophical Pepers II, p.134.

Romero, R. Ensayo: Nombrar para vivir, Ed. Voznostra, México, D. F., 2007.

-----, Ensayo: La invención de una nueva teoría en el tiempo, Voznostra, México, 2008.

Zizêk, S. El espinoso sujeto, Barcelona, Paidós, 2001.

------, La suspensión Política de la ética, FEC. Argentina, 2005. 
